\title{
Effects of septal stimulation in rats on heart rate and galvanic skin response '
}

\author{
T. L. HOLDSTOCK \\ WITWATERSRAND UNIVERSITY, JOHANNESBURG
}

Stimulation of the septal area of the brain resulted in pronounced heart rate deceleration and little or no galvanic skin response. The sudomotor findings were interpreted as an indication that heart rate slowing was chiefly due to sympathetic inhibition. Fibers of the fornix seem to be involved in the inhibitory process.

The few studies that have thus far Investigated the effect of reinforcing brain stimulation on the autonomic nervous system, reported heart rate (HR) slowing associated with intracranial self-stimulation of the septal area. However, the HR change seems to depend upon the location of the electrode within the septal complex. Lateral placements produced slowing while medial placements ylelded a brief initial speeding followed by slowing. The predominant effect nevertheless, is one of deceleration (Kasper, 1964; Malmo, 1961, 1963, 1964; Meyers, Valenstein, \& Lacey, 1963; Perez-Cruet, Black, \& Brady, 1963). Since HR is homeostatically controlled it is not clear whether the deceleration is due to pure vagal stimulation, to sympathetic inhibition from some area like the septum, or to a combination of the two effects. It was anticipated that the additional registration of the galvanic skin response (GSR) during septal stimulation would contribute to a better understanding of this problem, since the GSR is considered to be an uncomplicated indicator of sympathetic activity (Wang, 1957).

Method

A bipolar electrode was implanted in the septal area of each of 12 male albino rats (315-425 g). The electrode was inserted $1.0 \mathrm{~mm}$ anterior to the bregma, $0.6 \mathrm{~mm}$ lateral and $5.5 \mathrm{~mm}$ below the surface of the brain. At least two weeks were allowed for recovery.

The previously described procedure (Holdstock \& Schwartzbaum, 1965) of recording HR and GSR of the restrained animal was employed, using a Grass Model 5 D polygraph. A $0.5 \mathrm{sec}$ train of biphasic waves (pulse duration, $0.5 \mathrm{msec}$; frequency, $100 \mathrm{cps}$ ) was delivered by a Grass Model SD 5 stimulator. The initial voltage was set at $2.0 \mathrm{~V}$ and advanced in $1.0 \mathrm{~V}$ steps, sometimes up to $14.0 \mathrm{~V}$, and decreased in the same fashion. The interval between stimulations varied and was never less than $1 \mathrm{~min}$. A doorbell (50 dB re .0002 dyne $/ \mathrm{cm}^{2}$ ) was sounded intermittently for $0.5 \mathrm{sec}$ during the session. The tests were carried out in a darkened sound-attenuating chamber, separated from the programming equipment by a glass partition.

The HR response to the central and peripheral stimulation was expressed in relation to baseline scores.
Measurements of HR were obtained for 1-sec pertods: 1 sec prestimulation, 1st, 2nd, 3rd, and 4th sec poststimulation. Changes in interbeat interval (IBI) were derived by subtracting $1 \mathrm{sec}$ prestimulation from $1 \mathrm{sec}$ poststimulation values (see Holdstock, 1965, for a detailed discussion of the scoring procedure).

The sudomotor response to septal and auditory stimulation was defined as a percentage change in skin resistance from the baseline value immediately preceding the response onset to the lowest or highest value during 5 sec after stimulation.

Results

All the animals showed highly significant HR slowing to septal stimulation $(\mathrm{p}<.001$ for individual $\mathrm{Ss}, \mathrm{t}$ test for correlated means). The deceleration was already evident during the first sec after stimulation $(p<.001$, $t$ test), reaching a maximum during the third sec $(p<.001, t$ test). The average rate of slowing during the period of greatest deceleration was 50 beats per $\mathrm{min}$.

Septal stimulation failed to elicit GSR on 44 percent of the trials. On most of these trials skin resistance actually increased and in two animals the increase was significant $(p<.01$, Wilcoxon matched-pairs signedranks test). In six animals the change towards increased or decreased resistance was not significant, while a significant number of GSRs was observed in four of the animals (individual $p$ values being less than .05 and .01 by Wilcoxon's test).

In contrast, the doorbell elicited not only consistently more GSRs than the septal stimulation ( $\mathrm{p}<.01, \mathrm{X}^{2}$ test), but also GSRs of greater magnitude, even in the four Ss with a significant number of GSRs to septal stimulation.

The cardiac response to the sound stimulus, however, was slight and variable. It did not differ appreciably from patterns previously reported, but contrasted sharply with the response evoked by septal stimulation. Indeed, the marked cardiac deceleration together with a relatively small, or no GSR, was the outstanding result of the present study.

\section{Discussion}

That septal stimulation was ineffective in causing a GSR on 44 percent of the trials and that relatively small GSRs were elicited on the remaining trials, suggest that the HR slowing might have been due to inhibition of sympathetic activity, rather than to vagal stimulation. Observations made during the experiment provide additional support for this assumption, Quite frequently doorbell presentations within a few seconds after septal stimulation failed to eyoke GSRs. This occurred both at low and high intensities of central stimulation 


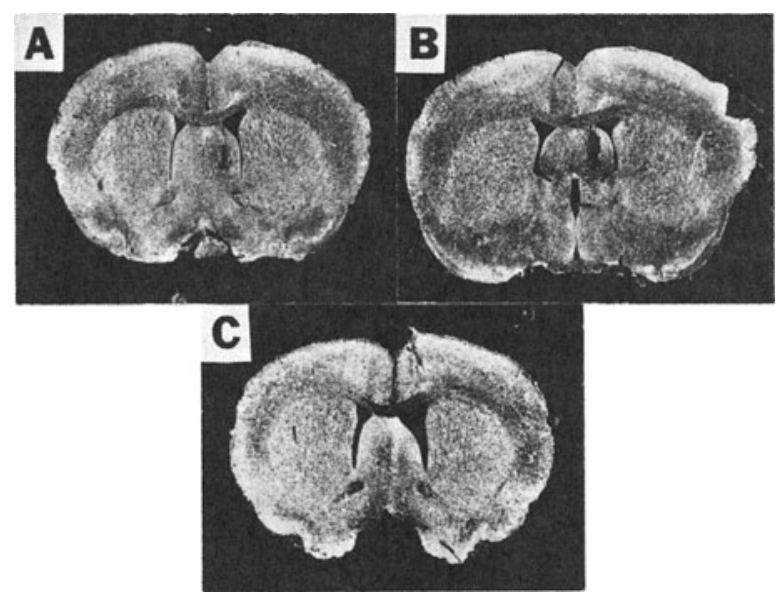

Fig. 1. Photomicrographs of unstained brain sections showing electrode placements in the lateral septal area at the level of: (a) the precommissural fornix, (b) columns of fornix, and (c) dorsal external septal nucleus.

and, in some instances, even though a GSR was elicited by the preceding septal stimulation. After repeatedly sounding the doorbell once every few seconds, a GSR was eventually evoked. This is probably due to dissipation of septal inhibition, as it contradicts known facts about adaptation. Since the inhibitory aftereffect was observed coincidentally, the relevant time and intensity parameters still need investigation.

In view of the anatomical relation between the septal area and hippocampal-fornix formation (Nauta, 1956), it is of interest to note that the effect of hippocampal stimulation on autonomic activity also supports an interpretation in terms of sympathetic inhibition. Yokota et al (1963) reported that inhibition of responses of skin potential and depression of blood pressure could be obtained by stimulation of the hippocampus and fornix. The depression elicited by the stimulation of these two structures did not disappear through atropinization, suggesting the existence of inhibition of vasomotor and sudomotor sympathetic activities.

Histological verification of electrode placements revealed a relationship between the number of GSRs and degree to which the placements in the lateral septal area Involved fibers of the fornix. Generally, fewer GSRs were observed in cases where the point of stimulation encroached upon the pre-commissural or columns of the fornix (Figs. 1A and 1B). This is in agreement with the work of Yokota et al (1963). The best evidence of HR deceleration without GSR was obtained with the point of stimulation in the area of the columns of the fornix. With one exception, the fornix was clearly less involved in placements that yielded a considerable number of GSRs. These points of stimulation were also in the lateral septal area, but just below the corpus callosum (Fig. 1C) or just above the anterior commissure.

The results of the present study do not preclude an interpretation of HR slowing as due to pure vagal stimulation or to some mixture of the effects of sympathetic inhibition and vagal stimulation. Experiments, at present under way, aim at resolving this issue by depriving animals of parasympathetic influence on the heart, either by atropine injection or vagal section.

References

HOLDSTOCK, T. L. Effects of septal lesions in rats on plasticity of autonomic functions. Unpublished doctoral dissertation, University of Wisconsin, 1965.

HOLDSTOCK, T. L., \& SCHWARTZBAUM, J. S. Classical conditioning of heart rate and galvanic skin response in the rat. Psychophysiology, 1965, 2, 25-38.

KASPER, P. Attenuation of passive avoidance by continuous septal stimulation. Psychon. Sci, 1964, 1, 219-220.

MALMO, R. B. Slowing of heart rate after septal self-stimulation in rats. Science, 1961, 133, 1128-1130.

MALMO, R. B. On central and autonomic nervous system mechanisms in conditioning, learning and performance. Canad. J. Psychol, 1963, $17,1-36$.

MALMO, R. B. Heart rate reactions and locus of stimulation within the septal area of the rat. Science, 1964, 144, 1-2.

MYERS, W. J., VALENSTEIN, E. S., \& LACEY, J. I. Heart rate changes after reinforcing brain stimulation in rats. Science, 1963, 140, 1233.

NAUTA, W. J. H. An experimental study of the fornix system in the rat. J. comp. Neurol, 1956, 104, 247-271.

PEREZ-CRUET, J., BLACK, W. C., \& BRADY, J. V. Heart rate: Differential effects of hypothalamic and septal self-stimulation. Science, $1963,140,1235$.

WANG, G. H. The galvanic skin reflex. A review of old and recent works from a physiologic point of view. Amer. J. physiol Med., 1957, 37, 35-57.

YOKOTA, R., SATOR, A., \& FUJIMORI, B. Inhibition of sympathetic activity by stimulation of limbic system. Jap. J. Physiol., 1963, 13, 138-144.

Note

1. This research was supported by a grant from the South African Council for Social Research. 